\title{
A Internacionalização da Educação Superior - Uma Pesquisa com Alunos Intercambistas Franceses e Brasileiros da FEA - Faculdade de Economia Administração e Contabilidade da USP
}

\author{
Edson Luiz Riccio e \\ Marici Gramacho Sakata*
}

Resumo: Recentemente, o estabelecimento de acordos acadêmicos entre a FEA/USP e a Universidades Francesas e as Grand Ecoles com o objetivo de promover o intercâmbio de alunos apresentou um enorme crescimento tanto quantitativo quanto qualitativo. Neste trabalho desenvolvemos um estudo de campo envolvendo os estudantes franceses que passaram pelo menos um semestre, e estudantes brasileiros que fizeram o mesmo na França com o objetivo de avaliar o impacto do intercâmbio acadêmico em suas vidas.

Palavras-chave: Internacionalização, Brasil, França, Educação Superior, FEA, Estudantes, Intercâmbio Internacional.

Abstract: Recently, the establishment of academic agreements between FEA/USP and French Universities and Grand Ecoles for students interchange has showed a great development both quantitatively and qualitative of the internationalization process of FEA/USP. We developed a field study with French Exchange students that spent at least one semester in FEA/USP and Brazilian Exchange students that did the same in France with the objective of evaluating the impacts of the academic interchange into their lives.

Keywords: Internationalization, Brazil, France, Higher Education, FEA, Students.

\footnotetext{
* Edson Luiz Riccio, Professor Livre-Docente da Faculdade de Economia, Administração e Contabilidade - FEA/USP, E-mail: elriccio@usp.br. Marici Gramacho Sakata, Doutoranda da Escola de Comunicações e Artes - ECA/USP, E-mail: mcsakata@usp.br. Recebido em 27/11/06 e aceito em 08/12/06.
} 


\section{Avaliação histórica da relação entre o Brasil e a França}

De acordo com Caldeira (2003) "O Brasil é uma das últimas províncias da terra onde ninguém é estrangeiro, onde é possível mudar um destino sem perder a identidade. E é essa, justamente, a característica que faz com que muitos o chame de "país do futuro". Talvez agora o Brasil possa ser visto como semente de uma realidade cultural onde o orgulho de grupo não está acima da possibilidade de aceitar o novo. Para o mais importante historiador brasileiro, Boris Fausto (2003), da formação do povo brasileiro,

tendo em conta as contribuiçôes de índios e negros, disso resultou uma população etnicamente diversificada, cujos valores e percepçóes variam de um segmento a outro, no âmbito de uma nacionalidade comum.

O Brasil foi uma Colônia de 1500 a 1822, depois se tornou Império de 1822 a 1889 e a partir de 1889 se tornou uma República. O maior fluxo de imigração ao Brasil se deu a partir de 1808 quando o país abriu seus portos às "nações amigas". Vieram imigrantes da Europa, do Oriente Médio e da Ásia - portugueses, italianos, espanhóis, alemães, judeus, sírios, libaneses e japoneses - e todos eles contribuíram para a característica étnica do povo. Por isso, a Globalização faz parte de todo o povo brasileiro. Estima-se que só no Estado de São Paulo encontram-se mais de 70 nacionalidades diferentes.

O início da relação entre o Brasil e a França data de 1504 quando Paulmier de Gonneville chegou ao Brasil com propósitos comerciais. Em 1555, foi estabelecida uma colônia de huguenotes denominada "França Antártica" para servir como refúgio para Calvinista como Nicolas de Durand Villegaignon. Em 1808, depois da abertura de portos para as naçóes amigas, a relação entre o Brasil e a França foi intensificada. Dentre os cientistas e artistas vindos da França para o Brasil que se destacaram, podemos citar: o astrônomo CharlesMarie de La Condamine, Auguste-Henri-Victor de Grandjean Montigny, Jean-Baptiste Debret e Zépherin Ferrez.

No século XVIII, o movimento de estudantes acadêmicos mudou do eixo de Coimbra para Paris e para outras cidades como Montpellier. Foi neste período que um brasileiro chamado Joaquim José da Silva Xavier (Tiradentes) conheceu as idéias do iluminismo que circulavam na França e 
também influenciado pela independência dos Estados Unidos tornou-se o principal articulador de um movimento, embora não sucedido, que visava instituir um governo republicano no Brasil. Isso se deu em 1789 e ficou conhecido como a Inconfidência Mineira. A França sempre deu boas-vindas os brasileiros. José Bonifácio de Andrade e Silva, um dos atores políticos na independência brasileira, foi exilado em Paris em 1823, depois da dissolução da Câmara no Rio de Janeiro.

A relação entre o Brasil e França também foi intensificada devido à criação do "Bureau des écoles et des œuvres françaises à l'étrange, em 1910", e do "Service des œuvres françaises à l'étranger" [SOFE] em 1920. Estes escritórios tinham a missão de introduzir a cultura francesa no Brasil e também trazer personalidades francesas ao cenário intelectual Brasileiro, como Claude-Lévi Strauss, Roger Bastide, e o historiador Fernand Braudel que vieram para o Brasil, contratados para lecionar na Universidade de São Paulo, fundada em 1936. Durante este período o acordo de "França et le Brésil de Convention littéraire, artistique et scientifique" foi assinado. Estas açóes resultarão em um aumento no comércio de livros, artes e moda com o Brasil devido à troca cultural estabelecida.

As trocas acadêmicas e institucionais tiveram um crescimento sem precedente com os acordos do CNRS-CNPq em 1975, e CAPESCOFECUB, em 1978. Desde então, acadêmicos brasileiros e franceses são convidados reciprocamente todos os anos. Uma Comissão Geral FrancoBrasileira foi criada através de um acordo em 1996 para coordenar os diversos aspectos das relaçóes bilaterais. A relação Franco-Brasileira na economia, política, e áreas culturais passam hoje pelo período mais intenso da história do relacionamento. Em 2005, foi coordenado pela Associação francesa para Ação Artística e os Ministérios de Cultura e Relação Exterior brasileiros o ano de Brasil na França. Através deste acordo foi criado um comitê comum com objetivo de guiar políticas francesas e brasileiras. Esta ação cultural teve como objetivo aumentar as ligaçóes históricas de amizade e paz entre os dois países (BRESILBRESILS, 2005). 


\section{Parcerias educacionais}

A colaboração entre a França e o Brasil na área de educação é consideravelmente alta e alguns programas já iniciaram há vários anos atrás. O governo brasileiro, por meio da CAPES (Coordenação de Aperfeiçoamento de Pessoal de Nível Superior), financia cerca de 500 bolsas de estudos para brasileiros irem estudar na França em várias áreas do conhecimento, entre elas Economia, Engenharia, Direito, Artes, etc. Outro programa específico de cooperação entre o Brasil e a França é a Capes/Cofecub. O programa está ativo a mais de 26 anos e já financiou estudos em nível de pós-graduação além aperfeiçoamento de professores e pesquisadores. Outro programa com a França é o Brafitec, implementado em 2002 para promover o intercâmbio de estudantes e o treinamento de professores nas disciplinas de Engenharia. A França, depois dos EUA, é o segundo destino de estudantes de pós-graduação. Quanto ao estudo da língua francesa, de acordo com as estatísticas da Aliança Française, hoje existem 60 escolas no Brasil que recebem 25.000 estudantes. No Brasil também há dois "lycèes" de ensino fundamental e médio.

Em dezembro de 2005, o Brasil e a França assinaram um acordo de cooperação internacional para pós-graduação. Ambos os Governos estabeleceram a criação do Colégio Doutoral Franco-brasileiro (CDFB). Este programa tem como objetivo receber estudantes de doutorado brasileiros e franceses nas escolas participantes e ter o Grau automaticamente reconhecido pelos dois países (CAPES, 2005).

De acordo com os dados da CAPES (2005) 17 projetos foram aprovados, resultando em 24 missóes de trabalho e 85 missóes de estudo, envolvendo um total de 222 estudantes brasileiros e franceses.

Várias faculdades e universidades brasileiras têm acordos com escolas e universidades francesas. A Universidade de São Paulo tem acordos nas áreas de Administração, Engenharia e Filosofia entre outros. A Universidade de São Paulo, (USP) é a maior instituição de ensino superior e pesquisa no Brasil, e a terceira em tamanho na América Latina. A USP é uma instituição de ensino superior de renome na América Latina, tendo formado uma grande quantidade de professores com graus de mestre e doutor que hoje são docentes em faculdades privadas e universidades por todo o Brasil.

De acordo com Novais (2005) a presença francesa no Brasil através das 
"missões" foi muito importante. Uma destas missóes foi a fundação da USP. Vários professores franceses vieram a USP e mais especificamente para a Escola de Filosofia. Entre eles estavam: Roger Bastide, Paul Arbousse-Bastide, Braudel, Lévi-Strauss e Pierre Monbeig entre outros e a presença deles foi decisiva para a modernização de Ciências Sociais no Brasil.

\section{O caso das Relações Internacionais na FEA - Faculdade de Economia, Administração e Contabilidade da USP}

A FEA-USP foi fundada em 1946. Em julho de 1986, a Comissão de Cooperação Internacional foi criada para cuidar dos assuntos relacionados a áreas internacionais. A CCInt FEA (Comissão de Cooperação Internacional da FEA) é o órgão responsável por estes assuntos dentro da Faculdade de Economia, Administração e Contabilidade da USP. A Comissão foi criada em 1992, e tem como objetivo desenvolver, promover e coordenar os programas internacionais da FEA, bem como "oferecer à comunidade FEA a possibilidade de entrar em contato com outras realidades educacionais, culturais e econômicas, bem como a divulgação do conhecimento científico produzido em nossa faculdade, os quais seriam impraticáveis sem a mediação desta Comissão" (Portal CCInt FEA). Hoje, a FEA USP possui mais de 78 acordos com 23 Países. Novas propostas são enviadas e recebidas constantemente.

A França está em primeiro lugar na lista de acordos com 15 do total de 78, representando 19\%. As escolas francesas com acordos de cooperaçáo (dezembro de 2005) são:

Bordeaux École de Management - BORDEAUX; ESC TOULOUSE - Toulouse; Euromed Marseille - MARSEILLE; IAE Grenoble GRENOBLE; ESC (Ecole Supérieure de Commerce) Rouen - ROUEN; IÉSEG (Instituto de Ensino de Ciências Econômicas e Gestão) School of Management - LILLE; ESCE (École Superieure de Commerce Extérieur) PARIS; Université de Pau et des Pays del’Adour-PAU; École de Management Lyon - LYON; ESC Chambéry - CHAMBERY; ISCID (Instituto Superior de Comércio Internacional de Dunkerque) DUNKERQUE - Dunkerque; ESSEC (École Superieure des Sciences Economiques et Commerciales) - 
CERGY-PONTOISE; ICN École de Management - NANCY; Grenoble École de Management - GRENOBLE; Sciences Po - PARIS.

O número de estudantes da FEA que participam em Programa de Intercâmbio, tem aumentado a cada ano. Em 2003, 84 estudantes participaram de programas de intercâmbio; em 2004, 89 estudantes; e em 2005, 111 Estudantes. Dos 111 estudantes que foram em 2005 para o exterior, 30 deles foram para a França, representando a maior concentração $(27,3 \%)$.

Considerando o número total de estudantes que participaram de programas de Intercâmbio, desde 1998, a França representa o primeiro destino dos estudantes da FEA seguida pela Suécia (com cursos em inglês), Alemanha, Holanda, Espanha, Portugal Inglaterra, Itália, EUA, Finlândia e Canadá entre outros.

Quanto aos estudantes estrangeiros que participaram de programas de Intercâmbio com a FEA, o número também tem crescido a cada ano. Em 2003, 67 estudantes participaram do programa, em 2004, 87 estudantes e em 2005, 94 estudantes. Do total de 94 estudantes que vieram para a FEA USP em 2005, 24 deles vieram da França, (25,5\%) representando a concentração maior.

Considerando o número total de estudantes estrangeiros que participaram programas em intercâmbio na FEA USP desde 1998 por países, novamente, os estudantes franceses são os mais representativos, seguidos pelos alemães, portugueses, holandeses, suecos, italianos, norte-americanos, canadenses, húngaros e mexicanos entre outros.

\section{Pesquisa empírica}

\section{Intercâmbio internacional - revisão de literatura}

Diversos países têm, há vários anos, encorajado suas universidades a estabelecerem acordos de intercâmbio com Universidades de outros países, entre estes acordos, o de troca de estudantes e professores, programas de pesquisa conjunta, duplo-diploma, além de outras atividades que ampliem o entendimento de outras culturas, valores, e sistemas educacionais (RICCIO, 
SAKATA, 2004). De acordo com Beed e Shooshtari (1998) aprender a trabalhar em uma economia global não é mais um luxo mas uma necessidade. Nota-se que as Instituições Educacionais começaram a responder a estas pressóes por meio de diferentes estratégias, e esta preocupação tem permanecido no topo da lista de prioridade. Uma das estratégias inclui as pressóes para a internacionalização da educação (MCCABE, 2001; ALTBACH, TEICHLER, 2001).

Foram publicados diversos artigos relativos à internacionalização de currículos de administração e contabilidade. Um estudo do IMA (2000) diz que, os estudantes de Contabilidade não estão expostos suficientemente à conceitos como globalização, tecnologia e ética. Nehrt (1987) analisou os resultados de quatro pesquisas relacionados a esforços de AACSB para internacionalizar o currículo de escolas de gestão. Um deles revelou que dos 564 cursos, apenas 64 implementaram programas de intercâmbio com escolas estrangeiras. Em 2005 este número está se invertendo.

Além da internacionalização da educação, é também importante entender o aspecto cultural (GREER, 2005), étnico e racial (BRYAN, 2005), comunicacional (KLIEGER, 2005) e de experiências pessoais (HOPKINS, 1999) que um programa de intercâmbio internacional envolve. Klieger (2005) fez um estudo focando a influência na tomada de decisão, as expectativas dos estudantes internacionais, e as experiências, e concluiu que os estudantes internacionais dependem de uma combinação de fatores que envolvem: amigos, família, e órgãos institucionais que os apóiem durante a transição para a vida no campus universitário estrangeiro.

Padróes como esses, fixados pela AACSB (The Association to Advance Collegiate Schools of Business), requerem que o currículo inclua assuntos globais. Outras associaçóes como a AAA (American Accounting Association) e AECC (Accounting Education Change Commission) também recomendaram atenção especial ao ensino da contabilidade e gestão internacional.

O objetivo dos Programas Internacionais é de desenvolver competências que serão necessárias durante a vida profissional dos estudantes. Como Boyatzis, Stubbs e Taylor (2002, p. 150) afirmam, preparar pessoas para serem destacados gestôes e líderes no ambiente global. 
A vida profissional implica em competências técnicas e pessoais. De acordo com Berdrow e Evers (2005), ela requer conhecimento empresarial, habilidades, engajamento com a educação continuada. A "base de competência” é um modelo que se concentra em habilidades gerais necessárias tanto para graduandos como para gestores. As bases de competência de Evers e Rush (1996) incluem:

a) Gestão pessoal: desenvolvimento constante de práticas e rotinas internas para maximizar a habilidade de lidar com a incerteza em um ambiente altamente variável: Requer habilidades como: Aprendizado constante; Organização do tempo; Forças pessoais e Solução de problemas.

b) Comunicação: interagir efetivamente com diversas pessoas e grupos para facilitar a coleta, integração, e tratamento de informação: Requer habilidades como: Relacionamento Interpessoal; Saber escutar; Comunicação oral; Comunicação escrita.

c) Administrar Pessoas e Tarefas: realizar tarefas planejando, organizando, coordenando e controlando recursos e pessoas. Requer habilidades como: Coordenação; Tomada de Decisão; Liderança; Administrar conflitos; Planejar e organizar.

d) Gerar Inovaçóes e Mudanças: conceituar e também dar início a mudanças e administrá-las principalmente as que envolvem cortes significantes do modo atual: Requer habilidades para conceituar: Criatividade; Inovação e Mudança; Risco; Visão.

Esta base de competências foi utilizada na pesquisa para analisar se os programas de intercâmbio estão colaborando para o desenvolvimento destas competências.

Pesquisas sobre intercâmbio acadêmico buscam entender as razóes (MACDONALD, 1974) e resultados (KITSANTAS, 2004) da mobilidade dos estudantes de uma região para outra. Esta pesquisa em especial foca mais nos resultados obtidos. Os resultados das perguntas feitas pelos autores mostram à intensidade da relação entre o Brasil e a França através das declaraçóes feitas pelos estudantes intercambistas. O caso da FEA USP é representativo uma vez que apresenta simetria nas relaçóes entre o Brasil e a 
França, o que permite uma análise contextual adequada.

\section{Método da pesquisa}

A pesquisa está baseada em três fontes de dados: 1) revisão de literatura; 2) declaração das escolas quanto aos objetivos dos Programas de Intercâmbio Internacional e 3) respostas dos estudantes que participaram dos programas. Ao término da pesquisa os resultados foram cruzados para a análise.

Foram coletadas as declarações das Comissōes de Cooperação Internacional das Faculdades de Administração disponíveis no site na internet. Foi realizada uma pesquisa qualitativa com uso de técnica de análise de conteúdo. A análise de conteúdo é considerada uma técnica sistemática, e replicável por comprimir diversas palavras de um texto em um número menor de categorias baseadas em regras explícitas de codificação como definida por Stemler (2001). Stemler (STEMLER, BEBELL, 1999) também realizou uma análise de conteúdo nas declaraçóes das missóes de escolas para analisar quais os razões principais de existência destas escolas.

Nesta pesquisa, através da codificação (categorias estabelecidas seguindo um exame preliminar dos dados), as categorias das declaraçóes das missóes das escolas em respeito de atividades de Intercâmbio Internacional foram:

- A exposição a outros modos de pensar

- Familiarização com estilos de ensino diferentes

- Enriquecimento da educação com um todo

- Relacionamentos internacionais

- Habilidades de um novo idioma

- Experiência intercultural

- Melhoria no currículo e habilidades para competir em uma ambiente global

A pesquisa empírica foi feita em uma amostra de 105 Estudantes da FEA USP que passaram um semestre ou mais em uma escola conveniada francesa (2000-2005) e 85 estudantes franceses que passaram um semestre ou mais na FEA USP (1999-2005) advindos de escolas conveniadas francesas.

Um questionário piloto foi aplicado e após a revisão, o questionário final 
foi enviado eletronicamente (e-mail) para os estudantes. A porcentagem de retorno dos questionários foi de 19\% (estudantes brasileiros) e $11 \%$ (estudantes franceses).

As categorias foram transformadas em perguntas fechadas variando de 1 a 10. Foi pedido para cada estudante que classificasse em uma escala de 1 a 10 (onde 1 significa "nada" e 10 "muito") as seguintes questóes que correspondem às categorias definidas acima:

1. Quão intensa foi sua exposição a novas formas de pensar? ( )

2. Quão intensa foi a diferença sentida no estilo de ensino? ( )

3. Qual o grau de enriquecimento de sua educação em geral com o intercâmbio? ( )

4. Quão freqüentemente você mantém contato com seus amigos franceses? ( ) 5. Quão fluente você diria que está agora para se comunicar em francês? ( )

6. Quão familiar a cultura Francesa é agora para você? ( )

7. Quanto essa experiência de intercâmbio impactou em sua atividade profissional? ( )

As seguintes questóes foram feitas no formato "Sim e Não" para analisar o quanto o programa contribuiu para sua atividade atual e se mantém relação com o país:

8. O seu período na França contribuiu de alguma maneira para a sua atividade atual? ( )

9. Sua atividade atual tem qualquer relação com a França? ( )

E uma última pergunta aberta foi feita:

10. Quantos períodos de intercâmbio você fez? ( ) Onde?

\section{Resultados}

$\mathrm{O}$ número de respondentes até o fechamento da pesquisa foi de 18 estudantes franceses $(21,1 \%)$ e 23 estudantes brasileiros $(21,9 \%)$. A Tabela 1 mostra os dados quantitativos. 
Tabela 1 - Resultados - dados quantitativos

\section{Questóes}

1. A exposição a outros modos de pensar

2. Diferença em estilos de ensino

3. Enriquecimento da educaçáo com um todo

4. Relacionamentos pessoais internacionais

5. Habilidades em um novo idioma

6. Experiência intercultural

7. Melhoria no currículo e habilidades para competir em uma ambiente global

8. O seu período na França contribuiu de alguma maneira para a sua atividade atual?

9. Sua atividade atual tem qualquer relação com a França?

10. Quantos períodos de intercâmbio você fez?

\begin{tabular}{c|c}
$\begin{array}{c}\text { Estudantes Franceses no } \\
\text { Brasil (n=18) }\end{array}$ & $\begin{array}{c}\text { Estudantes Brasileiros na } \\
\text { França }(\mathbf{n}=\mathbf{2 3})\end{array}$ \\
6,88 & $\mathbf{8 , 0 0}$ \\
6,02 & 6,08 \\
7,27 & (menor) 8,65 \\
(menor) 3,94 & (maior) 4,65 \\
\hline 7,22 & 7,60 \\
\hline (maior) 7,61 & 7,86 \\
\hline 6,88 & 7,04 \\
\hline $12=$ sim & $13=$ sim \\
$6=$ não & $10=$ não \\
$5=$ sim & $5=$ sim \\
$13=$ não & $18=$ não \\
$7=$ sim & $4=$ sim \\
$11=$ não & $19=$ não \\
\end{tabular}

Os dados mostram que tanto os estudantes franceses quanto os brasileiros, no que se referem à intensidade das relações pessoais tiveram uma freqüência baixa (isto será discutido posteriormente junto com dados qualitativos). A freqüência mais alta se deu em itens diferentes nos dois grupos. Os estudantes franceses consideram estarem mais familiarizados com a cultura brasileira, enquanto os brasileiros consideraram que tiveram um maior enriquecimento em sua educação como um todo. Estes resultados preliminares levantam uma importante questão sobre a intensidade das relaçóes interpessoais que se estabelecem durante os programas de intercâmbio.

As respostas dos dois grupos foram relativamente próximas quando ao impacto da experiência para a atividade profissional e para a exposição a idéias novas (alto) e diferença de estilos de ensino (baixo). A fluência do Idioma foi mais intensa para os brasileiros que para os franceses.

Foi deixado livre aos respondentes fazerem quaisquer comentários adicionais sobre o Programa de Intercâmbio. Os comentários foram muito interessantes e confirmaram os dados quantitativos adicionando novas idéias para pesquisa futura. Foi feita uma análise de conteúdo e foram encontrados os seguintes resultados:

Para os estudantes brasileiros, as palavras, Experiência, Trabalho, Cultura 
e Idioma apareceram com freqüências similares. As palavras como "pessoal”, "relação" apareceram raras vezes. Os comentários foram valiosos, pois os estudantes de intercâmbio aproveitaram a oportunidade para expressar o reconhecimento ao trabalho das pessoas envolvidas no escritório que tornaram esta experiência possível. A melhoria na educação e currículo foram citadas diversas vezes o que significa que a missão das escolas com os programas de intercâmbio têm sido cumpridas. Os estudantes também consideram a oportunidade importante por transformá-los em profissionais capazes de trabalhar no mercado global. Dois deles relataram estar trabalhando no exterior no momento e alguns informaram ter encontrado boas posiçóes em companhias devido à experiência internacional. A maioria dos estudantes não mantém contato com estudantes franceses e informam ter passado mais tempo com outros estudantes internacionais durante o período na França. Eles relataram algumas dificuldades em fazer amizade com os colegas do local, ou seja, os franceses.

Quanto aos estudantes franceses, os comentários adicionais estão relacionados principalmente a sentimentos. A análise de conteúdo mostrou que as palavras como "amor", "sonho", "a melhor época", "desfrutar", “o melhor momento de minha vida" e "tristeza", entre outros era mais freqüente que outros. Foram citadas duas vezes cada uma das expressóes: "a experiência abriu minha", "oferta de trabalho" e "melhora na educação". Os respondentes também informaram uma falta de relacionamento com os brasileiros, embora tenham tido um bom relacionamento com outros estudantes estrangeiros. Um estudante disse que o programa de intercâmbio o ajudou profissionalmente e no momento está trabalhando no México devido a sua experiência na América Latina.

\section{Conclusões}

Os resultados de pesquisa foram cruzados com a revisão de literatura e com o modelo de competências do administrador. O objetivo era avaliar se e como a experiência internacional contribuiu para o desenvolvimento de competências.

A literatura considera que o estudo no exterior provê Desenvolvimento Pessoal (KAUFFMANN, KUH, 1984) e Experiências Pessoais (HOPKINS, 
1999), o qual em termos de Competência significa "forças pessoais". A organização e habilidade para lidar com ambiente mutável, correspondem à competência gerenciamento pessoal e os estudantes confirmaram que eles foram expostos a novas formas de pensar. O programa foi (para a maioria deles) a experiência mais rica de suas vidas. Também é possível considerar que a percepção e o entendimento de uma cultura nova (KITSANTAS, 2004; STEPHENSON, 1999; GREER, 2005) possa aumentar esta competência. Ambos os grupos confirmaram que eles estão agora mais familiarizados com os aspectos culturais do país visitado.

Em relação às habilidades de Comunicação (KLIEGER, 2005) e aquisição de segunda língua (WATZKE, 1998) como apresentado na literatura, esta corresponde à competência de comunicação que se refere a interação Interpessoal efetiva com uma variedade de indivíduos e grupos, comunicação Oral e Escrita. Os resultados mostraram que tanto os franceses como os brasileiros melhoraram a fluência no idioma. Porém, os estudantes franceses informaram que têm poucas oportunidades de praticar o idioma e este não apareceu como um item importante comparando com os estudantes brasileiros. A comunicação interpessoal recebeu a mais baixa posição para ambas as nacionalidades. Os estudantes informam isso durante o período no estrangeiro eles tiveram mais contatos com estudantes estrangeiros do mundo inteiro e não com os do local. Ambos informaram ter tido dificuldades para estabelecer amizade com os estudantes do local. Este resultado pode ser explicado por muitas razóes e merece ser analisado posteriormente.

A habilidade para trabalhar em uma economia global é a meta principal dos Programas Internacionais e é discutida na literatura. Podemos relacionar esta habilidade com duas competências: Gerar Inovaçóes e mudanças e Administrar pessoas e tarefas. Os resultados mostraram que a experiência de estudar no exterior teve um impacto alto no papel profissional e, para mais que $50 \%$ deles, a experiência contribuiu para sua atividade atual.

\section{Discussão final}

A pesquisa revelou alguns elementos interessantes para estudos adicionais. Confirmou que os programas de intercâmbio melhoram a educação como um todo, tanto na visão dos estudantes como também confirmado por outros 
trabalhos de pesquisa apresentados na literatura. Porém, também revelou que a rede de relacionamentos criada pelos estudantes não está contemplando as pessoas do país anfitrião. Os estudantes em ambos os grupos informaram ter tido dificuldade em fazer e manter amizades com os colegas locais. As amizades ocorreram na maioria com colegas também intercambistas de outros países que estavam participando de programa de intercâmbio. Relativamente às relaçóes entre o Brasil e a França através do programa de intercâmbio, este tem sido bom nos aspectos profissionais, educacionais e culturais, mas não interpessoais com a mesma intensidade. 


\section{Referências Bibliográficas}

ALTBACH, Philip.; TEICHLER, Ulrich. Internationalization and exchanges in a globalized university. Journal of Studies in International Education, v. 5, n. 1, p. 5-25, Spring. 2001.

BEED, Teresa K.; SHOOSHTARI, Nader H. International accounting education: behind, but catching up? National Public Accountant, v. 43, issue 1, p. 47, Jan./Feb. 1998.

BERDROW, Iris; EVERS, Frederick. Competency-based course design. 2005. Available at: http://web.bentley.edu/empl/b/iberdrow/docs/ CompBasedCourseDesign_comp.doc. Access in: 28 Dec. 2005.

BOYATZIS, Richard E.; STUBBS, Elizabeth C.; TAYLOR, Scott N. Learning cognitive and emotional intelligence competencies through graduate management education. Academy of Management Learning \& Education, v. 1, n. 2, p. 150-162, 2002.

BRESILBRESILS.ORG. Les relations Franco-brésiliennes, 2005. Available at: http://www.bresilbresils.org/decouverte_bresil/index.php?page=relation/ palmier. Access in: 20 Dec. 2005.

BRYAN, William Ross. Effects of a study abroad experience on student views of whiteness. Dissertation at The University of North Carolina at Chapel Hill, 2005. Available at: http://proquest.umi.com/pqdweb?index $=83 \&$ did $=888$ $839261 \&$ SrchMode $=1 \&$ sid $=2 \&$ Fmt $=2 \&$ VInst $=$ PROD $\&$ VType $=$ PQD $\&$ $\mathrm{RQT}=309 \& \mathrm{VName}=\mathrm{PQD} \& \mathrm{TS}=1135598321 \&$ clientId=1811. Access in: 26 Dez. 2005.

CALDEIRA, Jorge. Brasil em Foco. Ministry of External Relations, 2003. Disponível em: http://www.mre.gov.br/cdbrasil/itamaraty/web/port/. Acesso em: 10 oct. 2005.

CAPES. Novo programa de pós-graduação entre Brasil e França é assinado em Paris, 2005. Disponível em: : http://64.233.187.104/search?q=cache: DInzYCZ6RQJ:www.capes.gov.br/capes/portal/conteudo/10/N01_ 11102005 S.htm+dados+estudantes+brasileiros+na+fran $\% \mathrm{C} 3 \% \mathrm{~A} 7 \mathrm{a} \& \mathrm{hl}=\mathrm{pt}$ -BR. Acesso em: 22 dec. 2005. 
EVERS, Frederick T.; RUSH, James C. The bases of competence: skill development during the transition from university to work. Management Learning, v. 27, n. 3, p. 275-299, 1996.

FAUSTO, Boris. Brasilem Foco. Ministry of External Relations, 2003. Disponível em: http://www.mre.gov.br/cdbrasil/itamaraty/web/port/. Acesso em: 10 oct. 2005.

GREER, Betty Jane. Overcoming academic challenges: the experiences of mainland Chinese graduate students at an American university. Dissertation at The University of Iowa, 2005. Available at: http://proquest.umi.com/ pqdweb? index $=100 \& \mathrm{did}=913517281 \&$ SrchMode $=1 \& \mathrm{sid}=1 \& \mathrm{Fmt}=2 \&$ VInst $=$ PROD \&VType $=P Q D \& R Q T=309 \& V N a m e=P Q D \& T S=1135$ 599411\&clientId=18110 Access in: 26 Dec. 2005

HOPKINS, J. Roy. Studying abroad as a form of experiential education. Liberal Education, v. 85, n. 3, p. 36-41, Sum. 1999.

IMA STUDIES. Improving Accounting Education IMA Studies, v. 16, n. 43, Aug. 2000.

KAUFFMANN, Norman L.; KUH, George D. The impact of study abroad on personal development of college students, 1984. Available at:: http://www. eric.ed.gov/ERICWebPortal/Home.portal?_nfpb=true\&eric_viewStyle=lis t\&ERICExtSearch_SearchValue_0=\%22Study+Abroad\%22\&ERICExtSe arch_SearchType_0=kw\&pageSize=10\&eric_displayNtriever=false\&eric_ displayStartCount $=41 \& \_$pageLabel=RecordDetails\&objectId $=0900000 \mathrm{~b} 8$ 0118f61. Access in: 23 Dec. 2005.

KITSANTAS, Anastasia. Studying abroad: the role of college students' goals on the development of cross-cultural skills and global understanding. College Student Journal, v. 38, n. 3, p. 441, Sep. 2004.

KLIEGER, Claire Jansen. A tangled web: international students, study abroad, and internationalization at an American university. Dissertation at University of Pennsylvania, 2005. Available in: http://proquest.umi.com/ pqdweb? index $=16 \&$ did $=921024831 \&$ Srch Mode $=1 \&$ sid $=4 \& \mathrm{Fmt}=2 \&$ VInst $=$ PROD \&VType $=$ PQD $\& R Q T=309 \& V N a m e=P Q D \& T S=11355$ 93797\&clientId=18110. Access in: 26 Dec. 2005. 
MACDONALD, Michael H. Study abroad: recommended, but proceed with caution, 1974. Available in: http://www.eric.ed.gov/ ERICWebPortal/Home.portal?_nfpb=true\&eric_viewStyle=list\&ERI CExtSearch_SearchValue_0=\%22Study+Abroad\%22\&ERICExtSearc h_SearchType_0=kw\&pageSize=10\&eric_displayNtriever=false\&eric_ displayStartCount=71\&_pageLabel=RecordDetails\&objectId=0900000b8 00efbd7. Access in: 23 Dec. 2005.

MCCABE, Lester T. Globalization and internationalization: the impact of education abroad programs. Journal of Studies in International Education, v. 5, n. 2, Summer 2001.

NEHRT, Lee C. The internationalization of the curriculum. Journal of International Business Studies, Spring, 1987.

NOVAIS, Fernando. Braudel e a "Missão Francesa". Entrevista publicada em Estudos Avançados/USP, 2005.

RICCIO, Edson Luiz; SAKATA, Marici Gramacho. Globalization and internationalization in accounting education. Proceedings of 27th European Accounting Conference, Prague, 2004.

STEMLER, Steve. An overview of content analysis. Practical assessment, research \& evaluation, v. 7, n. 17, 2001. Retrieved December 26, 2005 Available at: http://PAREonline.net/getvn.asp?v=7\&n=17.

STEMLER, Steve; BEBELL, Damian. An empirical approach to understanding and analyzing the mission statements of selected educational institutions, $\mathrm{p}$. 37, 1999. Available at: http://eric.ed.gov/ERICWebPortal/Home.portal?_ $\mathrm{nfpb}=$ true\&ERICExtSearch_SearchValue_0=\%22Stemler+Steve\%22\&ER ICExtSearch_SearchType_0=au\&_pageLabel=RecordDetails\&objectId=09 00000b80092be0\&accno=ED442202\&_nfls=false.

STEPHENSON, Skye. Study abroad as a transformational experience and its effect upon study abroad students and host nationals in Santiago, Chile. Frontiers: The Interdisciplinary Journal of Study Abroad, v. 5, n. 2, p. 1-38, Fall. 1999. 
WATZKE, John. Language Gains during study abroad: a reassessment of the "Predictors" study and prospects for future research. Proceedings of AATSEEL National Meeting held in San Francisco, CA, 27-30 December 1998. Available at: http://aatseel.org/program/1998/abstracts/John_Watzke. html. Access in: 10 Oct. 2006. 